\title{
Impact of concomitant vasoactive treatment and mechanical left ventricular unloading in a porcine model of profound cardiogenic shock
}

Nanna L. J. Udesen ${ }^{1 *}$ D, Ole K. L. Helgestad', Ann B. S. Banke ${ }^{1}$, Peter H. Frederiksen', Jakob Josiassen², Lisette O. Jensen ${ }^{1}$, Henrik Schmidt ${ }^{3}$, Elazer R. Edelman ${ }^{4,5}$, Brian Y. Chang ${ }^{4}$, Hanne B. Ravn ${ }^{6}$ and Jacob E. Møller ${ }^{1,2}$

\begin{abstract}
Background: Concomitant vasoactive drugs are often required to maintain adequate perfusion pressure in patients with acute myocardial infarction (AMI) and cardiogenic shock (CS) receiving hemodynamic support with an axial flow pump (Impella CP).

Objective: To compare the effect of equipotent dosages of epinephrine, dopamine, norepinephrine, and phenylephrine on cardiac work and end-organ perfusion in a porcine model of profound ischemic CS supported with an Impella CP.

Methods: CS was induced in 10 pigs by stepwise intracoronary injection of polyvinyl microspheres. Hemodynamic support with Impella CP was initiated followed by blinded crossover to vasoactive treatment with norepinephrine $(0.10 \mu \mathrm{g} / \mathrm{kg} / \mathrm{min})$, epinephrine $(0.10 \mu \mathrm{g} / \mathrm{kg} / \mathrm{min})$, or dopamine $(10 \mu \mathrm{g} / \mathrm{kg} / \mathrm{min})$ for $30 \mathrm{~min}$ each. At the end of the study, phenylephrine $(10 \mu \mathrm{g} / \mathrm{kg} / \mathrm{min})$ was administered for $20 \mathrm{~min}$. The primary outcome was cardiac workload, a product of pressure-volume area (PVA) and heart rate (HR), measured using the conductance catheter technique. End-organ perfusion was assessed by measuring venous oxygen saturation from the pulmonary artery $\left(\mathrm{SvO}_{2}\right)$, jugular bulb, and renal vein. Treatment effects were evaluated using multilevel mixed-effects linear regression.

Results: All catecholamines significantly increased LV stroke work and cardiac work, dopamine to the greatest extend by $341.8 \times 10^{3}(\mathrm{mmHg} \times \mathrm{mL}) / \mathrm{min}[95 \% \mathrm{Cl}(174.1,509.5), p<0.0001]$, and $\mathrm{SvO}_{2}$ significantly improved during all catecholamines. Phenylephrine, a vasoconstrictor, caused a significant increase in cardiac work by $437.8 \times 10^{3}$ $(\mathrm{mmHg} \times \mathrm{mL}) / \mathrm{min}[95 \% \mathrm{Cl}(297.9,577.6), p<0.0001]$ due to increase in potential energy $(p=0.001)$, but no significant change in LV stroke work. Also, phenylephrine tended to decrease $\mathrm{SvO}_{2}(p=0.063)$ and increased arterial lactate levels $(p=0.002)$.
\end{abstract}

Conclusion: Catecholamines increased end-organ perfusion at the expense of increased cardiac work, most by dopamine. However, phenylephrine increased cardiac work with no increase in end-organ perfusion.

Keywords: Cardiogenic shock, Acute myocardial infarction, Vasopressor, Mechanical circulatory support, Cardiac work, Organ perfusion

\footnotetext{
* Correspondence: Nanna.louise.junker.udesen@rsyd.dk

'Department of Cardiology, Odense University Hospital, J. B. Winsløwsvej 4,

Odense C, Denmark

Full list of author information is available at the end of the article
}

\section{$\triangle B M C$}

(c) The Author(s). 2020 Open Access This article is licensed under a Creative Commons Attribution 4.0 International License, which permits use, sharing, adaptation, distribution and reproduction in any medium or format, as long as you give appropriate credit to the original author(s) and the source, provide a link to the Creative Commons licence, and indicate if changes were made. The images or other third party material in this article are included in the article's Creative Commons licence, unless indicated otherwise in a credit line to the material. If material is not included in the article's Creative Commons licence and your intended use is not permitted by statutory regulation or exceeds the permitted use, you will need to obtain permission directly from the copyright holder. To view a copy of this licence, visit http://creativecommons.org/licenses/by/4.0/. The Creative Commons Public Domain Dedication waiver (http://creativecommons.org/publicdomain/zero/1.0/) applies to the data made available in this article, unless otherwise stated in a credit line to the data. 


\section{Introduction}

Reversing the vicious cycle of critically low cardiac output $(\mathrm{CO})$ and perfusion pressure in acute myocardial infarction and cardiogenic shock (AMICS) remains challenging, leading to sustained mortality of approximately $50 \%$ for the last few decades [1-5]. Hemodynamic support strategies aim to restore central perfusion using vasoactive drugs as first-line therapy [6], followed by the use of mechanical circulatory support devices $[7,8]$. Exogenous catecholamines stimulating $\alpha$ - and/or $\beta$-adrenergic receptors are administrated in about $90 \%$ of AMICS cases $[1$, 9]. However, observational studies suggest that high dosage and prolonged use of vasoactive drugs are associated with increased mortality $[10,11]$. $\beta$-Adrenergic agonists improve inotropic and chronotropic state, thus improving CO by enhancing myocardial contractility and increasing heart rate (HR) [12]. Although the use of vasoactive drugs to increase perfusion pressure and flow is theoretically beneficial in AMICS, it comes at the expense of increased left ventricular (LV) mechanical work with the potential to accelerate myocardial ischemia and induce arrhythmias [6]. Vasoconstriction without a concomitant increase in CO may also aggravate organ hypoperfusion [13]. Mechanical circulatory support devices seem appealing and are increasingly used in AMICS to overcome the potential adverse effects and limitations of catecholamines [1, 14]. The Impella $\mathrm{CP}$ is a transvalvular axial flow pump with the inlet placed in the LV and the outlet in the ascending aorta and is capable of pumping up to $3.5 \mathrm{~L} / \mathrm{min}$ oxygenated blood from the LV to the aorta. The forward flow increases systemic and coronary perfusion while reducing cardiac work [15]. Despite Impella support, additional pharmacological support is often necessary to maintain adequate perfusion pressure $[10,16]$, and the optimal vasoactive drug choice is currently unknown.

Thus, this study aimed to compare cardiac work and end-organ perfusion during infusion of equipotent dosages of four commonly used vasoactive agents (epinephrine, dopamine, norepinephrine, and phenylephrine) in pigs with experimentally induced CS supported by the Impella CP device.

\section{Methods}

\section{Animals}

Ten female Danish Landrace pigs weighing approximately $70 \mathrm{~kg}$ were studied. The study was approved and conducted per guidelines of the Danish Animal Experiments Expectorate (authorization number: 2016-15-00951). Unfractionated heparin $(20 \mathrm{IU})$ was administered every $2 \mathrm{~h}$ to avoid blood clotting during the experiment. Amiodarone $(300 \mathrm{mg}$ ) was injected before instrumentation followed by continuous infusion of $50 \mathrm{mg} / \mathrm{h}$ to avoid malignant arrhythmias. Instrumentation was done using the percutaneous Seldinger technique, except for the surgical exposure of the internal jugular vein. Instrumentation included placement of a conductance catheter (Ventri-Cath 512 PV Loop Catheter, Millar Inc.) in the LV for continuous recordings of pressure-volume (PV) relationships, a conductance catheter in the aorta to measure aortic pressure, a central line, and a continuous $\mathrm{CO}$ 7.5-Fr Swan-Ganz catheter with $\mathrm{SvO}_{2}$ recording (Edwards Lifesciences Corp. Irvine, CA, USA) placed in the pulmonary artery. A conventional triple lumen 7-Fr Swan-Ganz catheter (Edwards Lifesciences Corp. Irvine, CA, USA) was placed in the renal vein via femoral venous access, and a 4-Fr double-lumen central venous catheter (Cook Medical, Bloomington, USA) in a retrograde fashion in the internal jugular vein to obtain organ-specific blood gasses for measuring oxygen saturation and lactate levels.

\section{Experimental protocol}

Before the start of the study, a sealed envelope listing the order of the infusions of epinephrine, norepinephrine, and dopamine was handed to an independent individual who prepared and labeled the infusions with a number signifying the order. The infusions were prepared and administered at fixed infusion rates to what was considered equipotent doses and not to target a predefined MAP, equivalent to a dose of norepinephrine $0.10 \mu \mathrm{g} / \mathrm{kg} / \mathrm{min}$, dopamine $10 \mu \mathrm{g} / \mathrm{kg} / \mathrm{min}$, epinephrine $0.10 \mu \mathrm{g} / \mathrm{kg} / \mathrm{min}$, and phenylephrine $10 \mu \mathrm{g} / \mathrm{kg} / \mathrm{min}$. The infusion of phenylephrine alone was not blinded given the long half-life and administered in all pigs in the end. All animals were treated with a fluid regime of $1 \mathrm{~L}$ of isotonic saline the first hour and afterwards $900 \mathrm{~mL} / \mathrm{h}$, which was shifted between Ringer acetate and isotonic saline.

CS was induced by stepwise injection of polyvinyl alcohol microspheres (Contour ${ }^{\mathrm{Tw}}$, Boston Scientific, Marlborough, MA, USA) in the left main coronary artery through a JL3.5 guide catheter (Launcher, Medtronic Inc., Minneapolis, MN, USA) [17]. Hemodynamics were allowed to stabilize for 2-3 min after each injection before the administration of the next injection. Stepwise injections of microspheres was continued until CS developed, defined as mixed venous oxygen saturation $\left(\mathrm{SvO}_{2}\right)$ reduction to $<$ $30 \%$ or $\leq 50 \%$ of baseline value and/or sustained cardiac index $<1.5 \mathrm{~L} / \mathrm{min} / \mathrm{m}^{2}$ for $\geq 10 \mathrm{~min}$. A median of 12 microsphere injections (interquartile range, 9-17) was required to induce CS. Following the onset of CS, Impella CP was advanced from the left femoral artery and placed across the aortic valve with the inlet in the left ventricle and outlet in the ascending aorta. The placement of Impella CP was guided by fluoroscopy, and the maximum pump speed possible was achieved and maintained during the entire study. Vasoactive treatment with norepinephrine, dopamine, or adrenaline was randomized, and the treating team was blinded to the treating order. The first vasoactive infusion started following $30 \mathrm{~min}$ of Impella CP 
support, and each infusion was administered for $30 \mathrm{~min}$. The initial experimental plan included an Impella CP only phase (no vasoactive drugs) for 30 mins and a washout phase (no infusion of vasoactive drugs) between each drug infusion. However, due to severe hypotension (mean arterial blood pressure (MAP) $<50 \mathrm{mmHg}$ ) during the Impella alone and washout phase in the pilot pigs, the experimental protocol was changed and Impella support was combined with a minimum dose of norepinephrine to maintain MAP $>50 \mathrm{mmHg}$. Also, the withdrawal and initiation of subsequent drug infusion overlapped to avoid any drop in arterial pressure. Vasoactive drug infusion was withdrawn following any change in hemodynamics (mean arterial pressure or heart rate). Phenylephrine was administered in all pigs for $20 \mathrm{~min}$ after the completion of all three catecholamine infusions, followed by euthanization.

\section{Data collection and analysis}

\section{Pressure volume parameters}

A conductance catheter was inserted through a sheath in the right carotid artery and advanced retrograde into the LV and connected to an MPVS Ultra Pressure-Volume (PV) loop system (Millar Inc., 6001 Gulf Fwy, Houston, TX, USA). The PV relationships were available in 9 pigs at all time points and not available in 1 pig due to disturbance in the volume signal. The MPVS Ultra PV loop system was connected to a PowerLab 16/35 (ADInstruments, Dunedin, New Zealand), and PV measurements were continuously recorded in LabChart Pro (ADInstruments, Dunedin, New Zealand). Volumes were calibrated using an alpha correctional value, and parallel wall conductance was determined using the hypertonic saline method. Data recorded from the conductance catheter comprised of the following: pressurevolume area $(\mathrm{PVA}, \mathrm{mmHg} \times \mathrm{mL}), \mathrm{LV}$ end-diastolic pressure (LVEDP, $\mathrm{mmHg}$ ), LV end-diastolic volume (LVEDV, $\mathrm{mL}$ ), LV end-systolic pressure (ESP), LV stroke work (SW, $\mathrm{mmHg} \times \mathrm{mL}$ ), LV end-systolic pressure-volume relationship (Ees), and heart rate (HR, bpm). In all the pigs, balloon occlusion of the inferior vena cava was performed in the healthy condition at the start of the study, and the acquired $V_{0}$ (theoretical ventricular volume when no pressure is generated) was kept as a constant throughout the study to generate single-beat estimations of Ees and PVA [18, 19]. Ees was derived from Ees $=$ LVESP/(LVESV-V0) [20]. Potential energy $(\mathrm{mmHg} \times \mathrm{mL})$ was estimated using the formula, $\mathrm{PE}=$ LVESP(LVESV-V0)/2 [21]. All other variables were extracted from the software program. The slope of the line from LVEDV to LVESP on the P-V loop was used to calculate arterial elastance (Ea). Ventriculo-arterial coupling was assessed as the ratio between Ea and Ees [22].

\section{Data collection}

Data were collected at seven prespecified time points: baseline before injection of microspheres, the onset of
CS before initiation of Impella support, after $30 \mathrm{~min}$ of Impella support, at the end of each blinded infusion, and after $20 \mathrm{~min}$ of phenylephrine infusion. Collected data included systemic and pulmonary artery blood pressure, central venous blood pressure, blood gasses assessing oxygen saturation and lactate levels from the femoral and pulmonary artery, and renal and internal jugular veins. PV relationships including LVEDP, LVEDV, LVESP, LVEDP, SW, potential energy, PVA, HR, Ees, and Ea were determined for the same time points.

\section{Efficacy parameters}

The primary efficacy parameters of the study were PVA and cardiac work $(\mathrm{HR} \times \mathrm{PVA})$, both parameters closely related to myocardial oxygen consumption [21]. Endorgan perfusion was estimated based on organ-specific (cerebral and renal) and overall venous saturations.

\section{Statistical analysis}

Baseline variables are presented as mean (95\% confidence interval (CI)). A linear mixed model (LMM) was constructed using individual pigs as subjects for random factors and sequential experimental stages as fixed repeated measurements. The LMM allowed the correlation between subjects and non-constant variability over time. It was used to calculate the change in a variable following an intervention compared to the control once the normal distribution of the variables residual was confirmed. A sensitivity analysis was conducted for an outlier to assess its effect on the overall interpretation of the results. All statistical tests were performed using STATA 15. A $p$ value $<0.05$ was considered significant.

\section{Results}

\section{Hemodynamic changes during CS and after $30 \mathrm{~min}$ of Impella support}

Following the induction of CS, defined as a $50 \%$ reduction in $\mathrm{SvO}_{2}$ and cardiac index $<1.5 \mathrm{~L} / \mathrm{min} / \mathrm{m}^{2}$, a significant increase in LVEDV and LVEDP was observed concomitant with a significant reduction in SW and stroke volume (Table 1 and Fig. 1). The systemic blood pressure was compromised with a mean MAP of $<40 \mathrm{mmHg}$, Table 1 .

Initiation of Impella $\mathrm{CP}$ resulted in a reduction of LVEDV by $33 \%$ and potential energy by $>40 \%$ with little change in SW (Table 1). The PV loop shifted leftward and became triangular (Fig. 1). Despite Impella support, the MAP remained $<50 \mathrm{mmHg}$ in 7 pigs. Hence, a low-dose norepinephrine (median $0.02 \mu \mathrm{g} / \mathrm{kg} / \mathrm{min}$ [interquartile range $0.02,0.05]$ ) was administered to increase MAP $>50$ $\mathrm{mmHg}$. Impella support reduced the cardiac work $(\mathrm{HR} \times$ PVA) via a reduction in both potential energy and HR (Table 1 and Fig. 1). Although Impella support increased renal, cerebral, and mixed venous saturations, the levels did not reach the baseline level, while the lactate levels did 
Table 1 Hemodynamic characteristics and organ perfusion at baseline, onset of cardiogenic shock, and after 30 min of Impella CP support

\begin{tabular}{|c|c|c|c|}
\hline \multirow[t]{2}{*}{ Variable } & Baseline & Cardiogenic shock & Impella 30 min \\
\hline & Mean $(95 \% \mathrm{Cl})$ & Mean $(95 \% \mathrm{Cl})$ & Mean $(95 \% \mathrm{Cl})$ \\
\hline Stroke work $(\mathrm{mmHg} \times \mathrm{mL})$ & $4853(3906,5801)$ & $703(350,1056)$ & $980(619,1340)$ \\
\hline Potential energy ${ }^{2}(\mathrm{mmHg} \times \mathrm{mL})$ & $4290(2887,5694)$ & $4567(2973,6161)$ & $2690(2019,3361)$ \\
\hline $\mathrm{PVA}^{1}(\mathrm{mmHg} \times \mathrm{mL})$ & $9143(7406,10,880)$ & $5270(3468,7072)$ & $3670(2780,4560)$ \\
\hline Heart rate $\left(\mathrm{min}^{-1}\right)$ & $82(75,89)$ & $81(75,87)$ & $75(69,82)$ \\
\hline LV work ${ }^{2} 10^{3} \times(\mathrm{mmHg} \times \mathrm{mL}) / \mathrm{min}$ & $751.7(595.2,906.1)$ & $430.3(271.3,589.2)$ & $274.2(206.9,341.5)$ \\
\hline Ees $^{3}(\mathrm{mmHg} / \mathrm{mL})$ & $1.42(1.06,1.79)$ & $0.40(0.3,0.5)$ & $0.74(0.57,0.92)$ \\
\hline $\operatorname{LVEDV}^{4}(\mathrm{~mL})$ & $156.1(133,179)$ & $188.8(154,224)$ & $125.2(108,142)$ \\
\hline $\operatorname{LVEDP}^{5}(\mathrm{mmHg})$ & $16(12.7,19.2)$ & $22(19.7,24.8)$ & $19(15,22)$ \\
\hline $\operatorname{LVESV}^{6}(\mathrm{~mL})$ & $91.1(69,113.2)$ & $162.7(130.2,195.2)$ & $97(82.4,111.5)$ \\
\hline $\operatorname{LVESP}^{7}(\mathrm{mmHg})$ & $104.87(91.4,118.3)$ & $58.35(48.8,67.9)$ & $61.65(50.5,72.9)$ \\
\hline Mean arterial pressure, $(\mathrm{mmHg})$ & $79(71,88)$ & $39(30,48)$ & $61(51,72)$ \\
\hline Right atrial pressure $(\mathrm{mmHg})$ & $9(7,11)$ & $14(10,17)$ & $12(9,14)$ \\
\hline Mean pulmonary arterial pressure $(\mathrm{mmHg})$ & $21(19,24)$ & $25(21,29)$ & $24(20,28)$ \\
\hline Arterial lactate $(\mathrm{mmol} / \mathrm{L})$ & $1.49(1.05,1.94)$ & $2.1(1.67,2.51)$ & $2.22(1.65,2.79)$ \\
\hline Mixed venous oxygen saturation (\%) & $76(69,82)$ & $37(30,44)$ & $55(47,64)$ \\
\hline Renal venous oxygen saturation (\%) & $89(85,92)$ & $58(42,75)$ & $73(62,85)$ \\
\hline Cerebral venous oxygen saturation (\%) & $79(73,85)$ & $45(35,55)$ & $59(48,71)$ \\
\hline Hemoglobin (mmol/L) & $6.4(5.7,7.1)$ & $5.6(5.1,6.2)$ & $6.1(5.6,6.6)$ \\
\hline
\end{tabular}

Data are presented as mean and $(95 \% \mathrm{Cl})$. Abbreviations: $P V A^{1}$ pressure volume area, $L V$ work ${ }^{2}$ left ventricular work equals heart rate $\times$ pressure volume area, Ees $^{3}$ left ventricular elastance, $L V E D V^{4}$ left ventricular end-diastolic volume, $L V E D P^{5}$ left ventricular end-diastolic pressure, $L V E S V^{6}$ left ventricular end-systolic volume, $L V E S P^{7}$ left ventricular end-systolic pressure

not change significantly during Impella support (Table 1 and Fig. 2). The $\mathrm{SvO}_{2}$ increased during Impella support from $37 \%(95 \%$ CI 39,44$)$ to $55 \%(95 \%$ CI 47,64$)$. A laminar aortic flow was observed after 30 mins of Impella support in four pigs, suggesting uncoupling between the ventricular and aortic peak pressure.

\section{Effect of vasoactive agents on cardiac workload during Impella support}

All vasoactive drugs caused a significant increase in PVA, albeit to different degrees. SW increased significantly with all catecholamines, but remained unchanged with phenylephrine. On the other hand, only phenylephrine caused a significant increase in potential energy. HR increased with all drugs, except for norepinephrine. Thus, cardiac work increased significantly with all vasoactive drugs (Table 2). The average effects on PV loops are summarized in Fig. 1. In general, catecholamines increased SW and reduced LVESV, thus causing a leftward shift of the PV loop. In contrast, phenylephrine caused a rightward shift of the PV loop with an increase in LVEDV and LVEDP (Fig. 1 and Table 2).

Also, phenylephrine significantly increased right atrial and mean pulmonary artery pressure, an effect not observed with any of the other vasoactive drugs (Table 2).

\section{Effect of vasoactive agents on end-organ perfusion during Impella support}

$\mathrm{SvO}_{2}$ increased with vasoactive drugs, except phenylephrine which caused a slight decrease [(mean difference from Impella alone), $-9 \%$ [95\% CI (-19\% to 0\%)], $p=$ 0.063] (Fig. 2). Renal venous saturations also decreased with phenylephrine while there was no change with any of the other drugs. Cerebral venous saturation increased significantly with dopamine, slightly with norepinephrine, and did not change with phenylephrine (Fig. 2). Signs of end-organ ischemia were observed with phenylephrine with a significant increase in arterial and venous lactate levels (Fig. 2). In contrast, the catecholamines did not cause any change in lactate levels, although there was a trend towards lower lactate concentration with norepinephrine $(p=0.06)$ (Fig. 2). The correlation between $\mathrm{SvO}_{2}$ and cardiac work during different stages of the study is shown in Fig. 3.

\section{Effect of vasoactive agents on ventricular-arterial coupling during Impella support}

CS was characterized by a decrease in Ees and an increase in ventriculo-arterial decoupling $(\mathrm{Ea} / \mathrm{Ees})$ from $1.3(1.3-2.0)$ to $7.2(3.8-10.6)$ (Table 1). Dopamine significantly increased Ees, but no significant changes were 


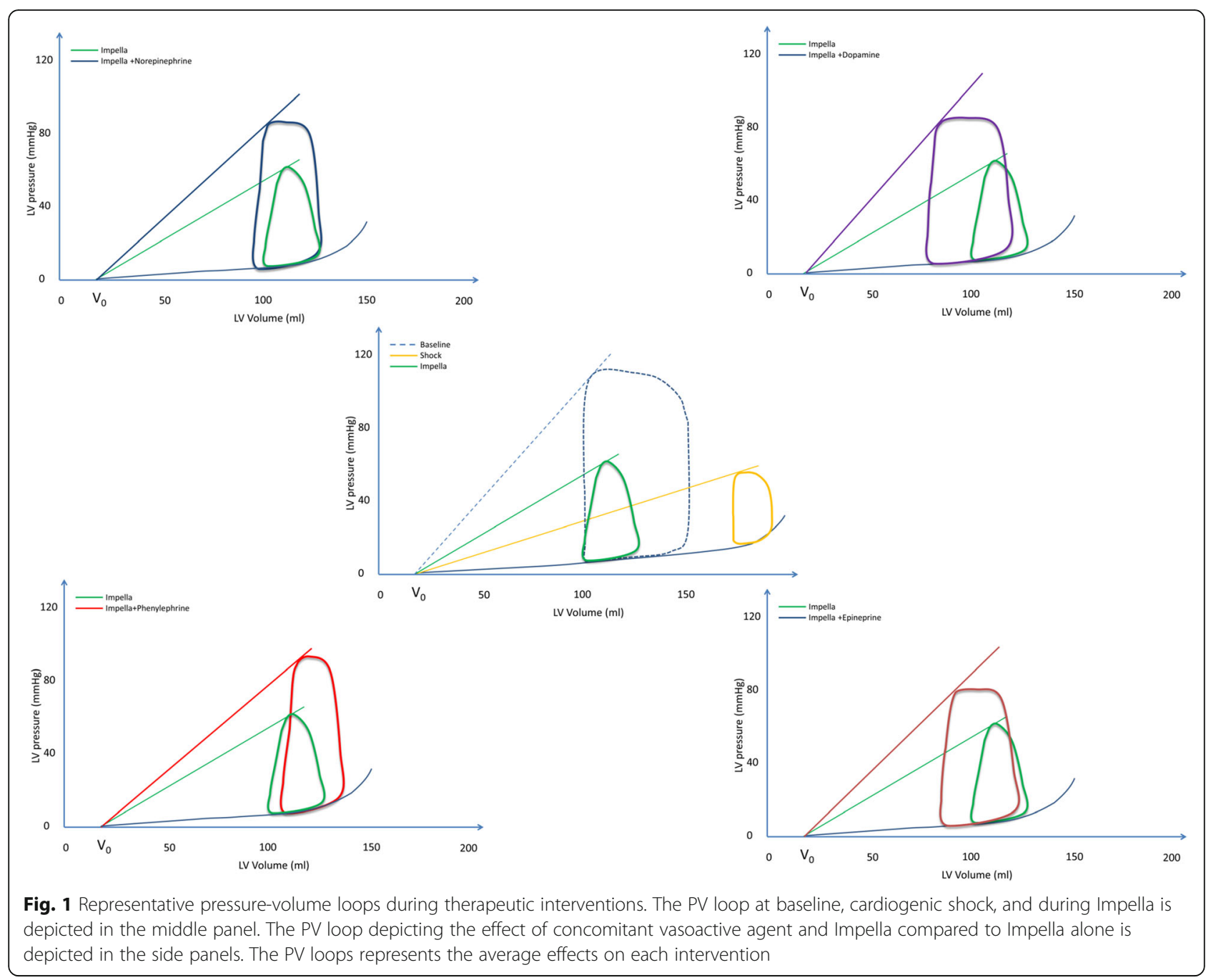

observed with all the other drugs. Phenylephrine significantly increased Ea (Table 2). Consequently, ventriculoarterial coupling significantly improved with dopamine $(p=0.03)$, a trend towards improvement was observed with epinephrine $(p=0.09)$, but remained unchanged with phenylephrine and norepinephrine.

\section{Discussion}

To our knowledge, this is the first study to compare the effect of equipotent doses of commonly used vasoactive agents in combination with a microaxial flow pump. Despite the increase in oxygen delivery with lowering of cardiac workload after initiation of Impella support, perfusion pressure was not restored in the majority of pigs, which is why additional vasoactive therapy seems unavoidable. The addition of a catecholamine increased LVESP and $\mathrm{SvO}_{2}$ but at the expense of increased cardiac work (most for dopamine). However, vasoconstriction with phenylephrine caused an increase in cardiac work without any increase in oxygen delivery (decreased $\mathrm{SvO}_{2}$ and increased arterial lactate). Thus, a support strategy based on Impella CP and low-dose catecholamine (norepinephrine) seems optimal to balance oxygen delivery and LV unloading.

Patients with AMICS have critically low blood pressures, which may aggravate tissue hypoxia and cause decreased coronary blood flow even in the non-infarcted myocardium if the vicious cycle is not interrupted [7]. Impella is used in AMICS to support the flow of oxygenated blood via continuous forward flow from the LV to the aorta, thereby augmenting CO while unloading the LV [14]. In this study, initiation of Impella support decreased cardiac work through a reduction in LV potential energy, and the PV loop shape changed to triangular (Fig. 1). Despite Impella support, the mean arterial pressure remained < $50 \mathrm{mmHg}$ in 7 of 10 pigs and oxygen delivery was although improved not restored to pre shock level (Fig. 3). However, increased blood pressure does not automatically translate into an increased oxygen delivery [23] as an increase in MAP can be obtained by increasing $\mathrm{CO}$ or 

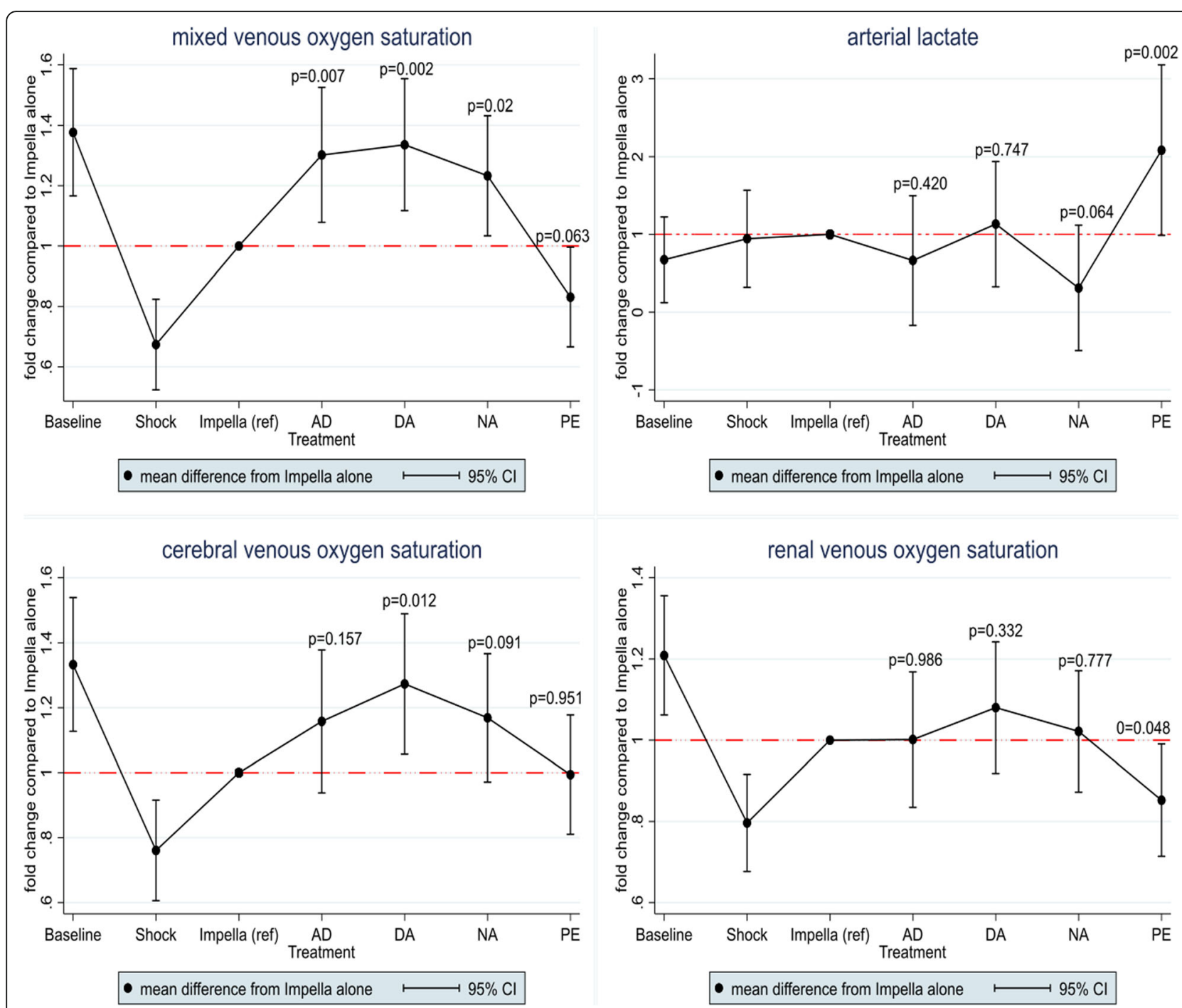

Fig. 2 End-organ perfusion. The relative mean difference during interventions compared to Impella alone. Impella alone is represented by the red dotted line. $A D$, epinephrine; $D A$, dopamine; $N A$, norepinephrine; $P E$, phenylephrine

vascular resistance via vasoconstriction [13]. Vasoactive agents can increase perfusion pressure by either stimulating cardiac $\beta$-adrenoceptors, thus enhancing $\mathrm{CO}$ or by stimulating vascular $\alpha$-adrenoceptors, causing an increase in systemic vascular resistance [24]. Since phenylephrine only stimulates the $\alpha$-adrenoceptors [25], it caused a high afterload and a significant increase in potential energy (energy wasting) with a rightward shift of the PV loop (Fig. 1) accompanied by reduced oxygen delivery and increased arterial lactate levels (Fig. 2). It is likely that the shift in preload, afterload, and increase in HR also led to compromised coronary blood flow. Overall, catecholamines improved oxygen delivery via an increase in both perfusion pressure and flow, but the associated LV energy costs varied among the different drugs. Particularly, dopamine increased cardiac work via an increase in both HR and PVA. The present study suggests that the optimal balance between maximum oxygen delivery and the least expense in cardiac work is achieved with norepinephrine where HR increased least (Fig. 3) and the beneficial effect is in accordance with other experimental findings [26].

The finding from this study that the Impella alone was insufficient to increase MAP and $\mathrm{SvO} 2$ to pre shock values is in line with observational studies reporting frequent use of concomitant vasoactive agents with Impella support in CS [10, 27-29]. Thus, vasoactive agents are often unavoidable for the treatment of AMICS supported by Impella $\mathrm{CP}$, irrespective of their potential side effects $[10,30]$. Currently, concomitant use of vasoactive agents during mechanical LV unloading in CS is based on expert consensus and local practice. Norepinephrine is recommended as the first-line therapy if perfusion pressure is low [31], mainly based on the Sepsis Occurrence in Acutely Ill Patients (SOAP-II) trial. The SOAP- 
Table 2 Mixed model values listed as mean difference from the reference time. The reference time was set to 30 min after initiation of Impella CP support

\begin{tabular}{|c|c|c|c|c|}
\hline & Epinephrine & Dopamine & Norepinephrine & Phenylephrine \\
\hline & $\begin{array}{l}\text { Mean difference } \\
(95 \% \mathrm{Cl})\end{array}$ & $\begin{array}{l}\text { Mean difference } \\
(95 \% \mathrm{Cl})\end{array}$ & $\begin{array}{l}\text { Mean difference } \\
(95 \% \mathrm{Cl})\end{array}$ & $\begin{array}{l}\text { Mean difference } \\
(95 \% \mathrm{Cl})\end{array}$ \\
\hline Stroke work $(\mathrm{mmHg} \times \mathrm{mL})$ & $\begin{array}{l}1175(279,2070) \\
p=0.01\end{array}$ & $\begin{array}{l}1974(1111,2838) \\
p<0.0001\end{array}$ & $\begin{array}{l}1086(260,1912) \\
p=0.01\end{array}$ & $\begin{array}{l}604(-116,1324) \\
p=0.1\end{array}$ \\
\hline Potential energy $(\mathrm{mmHg} \times \mathrm{mL})$ & $\begin{array}{l}324(-1016,1664) \\
p=0.636\end{array}$ & $\begin{array}{l}-53(-1346,1239) \\
p=0.936\end{array}$ & $\begin{array}{l}929(-306,2165) \\
p=0.140\end{array}$ & $\begin{array}{l}2220(1142,3298) \\
p<0.0001\end{array}$ \\
\hline PVA $(m m H g \times m L)$ & $\begin{array}{l}1506(121,2890) \\
p=0.033\end{array}$ & $\begin{array}{l}1928(593,3263) \\
p=0.005\end{array}$ & $\begin{array}{l}2023(746,3299) \\
p=0.002\end{array}$ & $\begin{array}{l}2824(1711,3938) \\
p<0.0001\end{array}$ \\
\hline Heart rate (BPM) & $\begin{array}{l}15(3,28) \\
p=0.016\end{array}$ & $\begin{array}{l}29(17,41) \\
p<0.0001\end{array}$ & $\begin{array}{l}3(-8,15) \\
p=0.554\end{array}$ & $\begin{array}{l}32(22,42) \\
p<0.0001\end{array}$ \\
\hline $\mathrm{LV}$ work $10^{3} \times(\mathrm{mmHg} \times \mathrm{mL}) / \mathrm{min}$ & $\begin{array}{l}202.2(28.3,376.1) \\
p=0.023\end{array}$ & $\begin{array}{l}341.8(174.1,509.5) \\
p<0.0001\end{array}$ & $\begin{array}{l}186.3(26,346.6) \\
p=0.023\end{array}$ & $\begin{array}{l}437.8(297.9,577.6) \\
p<0.0001\end{array}$ \\
\hline LVEDP $(\mathrm{mmHg})$ & $\begin{array}{l}3(-0.5,7) \\
p=0.086\end{array}$ & $\begin{array}{l}0(-3.4,3.8) \\
p=0.903\end{array}$ & $\begin{array}{l}1(-2.4,4.4) \\
p=0.571\end{array}$ & $\begin{array}{l}6(2.6,8.5) \\
p<0.0001\end{array}$ \\
\hline LVEDV $(\mathrm{mL})$ & $\begin{array}{l}-8(-30,15) \\
p=0.510\end{array}$ & $\begin{array}{l}-15(-37,7) \\
p=0.175\end{array}$ & $\begin{array}{l}0(-21,21) \\
p=0.978\end{array}$ & $\begin{array}{l}18(0.2,37) \\
p=0.047\end{array}$ \\
\hline LVESP $(\mathrm{mmHg})$ & $\begin{array}{l}23(7.1,39.6) \\
p=0.005\end{array}$ & $\begin{array}{l}29(13.6,44.8) \\
p<0.0001\end{array}$ & $\begin{array}{l}28(12.7,42.6) \\
p<0.0001\end{array}$ & $\begin{array}{l}34(21.3,47.4) \\
p<0.0001\end{array}$ \\
\hline LVESV (mL) & $\begin{array}{l}-23(-48,2) \\
p=0.074\end{array}$ & $\begin{array}{l}-36(-60,-12) \\
p=0.003\end{array}$ & $\begin{array}{l}-10(-33,12) \\
p=0.371\end{array}$ & $\begin{array}{l}14(-6,34) \\
p=0.170\end{array}$ \\
\hline Es $(\mathrm{mmHg} / \mathrm{mL})$ & $\begin{array}{l}0.75(-0.15,1.65) \\
p=0.101\end{array}$ & $\begin{array}{l}1.75(0.87,2.62) \\
p<0.0001\end{array}$ & $\begin{array}{l}0.42(-0.41,1.25) \\
p=0.324\end{array}$ & $\begin{array}{l}0.29(-0.44,1.01) \\
p=0.78\end{array}$ \\
\hline Ea $(\mathrm{mmHg} / \mathrm{mL})$ & $\begin{array}{l}-0.17(-1.64,1.3) \\
p=0.823\end{array}$ & $\begin{array}{l}-0.29(-1.71,1.13) \\
p=0.687\end{array}$ & $\begin{array}{l}0.57(-0.79,1.92) \\
p=0.411\end{array}$ & $\begin{array}{l}1.52(0.34,2.7) \\
p=0.012\end{array}$ \\
\hline Ea/Ees ratio & $\begin{array}{l}-2.3(-4.92,0.33) \\
p=0.086\end{array}$ & $\begin{array}{l}-2.81(-5.34,-0.28) \\
p=0.029\end{array}$ & $\begin{array}{l}-1.36(-3.78,1.06) \\
P=0.270\end{array}$ & $\begin{array}{l}1.13(-0.99,4.23) \\
p=0.296\end{array}$ \\
\hline Mean arterial pressure $(\mathrm{mmHg})$ & $\begin{array}{l}10(-3.9,23.9) \\
p=0.157\end{array}$ & $\begin{array}{l}20(6.4,33) \\
p=0.004\end{array}$ & $\begin{array}{l}13(0.8,25.7) \\
p=0.037\end{array}$ & $\begin{array}{l}6(-5.1,17.5) \\
p=0.282\end{array}$ \\
\hline Right atrial pressure $(\mathrm{mmHg})$ & $\begin{array}{l}-2(-3.6,0.2) \\
p=0.082\end{array}$ & $\begin{array}{l}-3(-5,-1.3) \\
p=0.001\end{array}$ & $\begin{array}{l}-2(-3.7,-0.3) \\
p=0.024\end{array}$ & $\begin{array}{l}2(0.4,3.5) \\
p=0.016\end{array}$ \\
\hline Mean pulmonary artery pressure $(\mathrm{mmHg})$ & $\begin{array}{l}-2(-7.3,4.3) \\
p=0.616\end{array}$ & $\begin{array}{l}2(-3.7,7.5) \\
p=0.513\end{array}$ & $\begin{array}{l}1(-3.7,6.1) \\
p=0.586\end{array}$ & $\begin{array}{l}9(4.7,14.1) \\
p<0.0001\end{array}$ \\
\hline Hemoglobin (mmol/L) & $\begin{array}{l}0.64(-0.16,1.45) \\
p=0.115\end{array}$ & $\begin{array}{l}0.52(-0.26,1.3) \\
p=0.193\end{array}$ & $\begin{array}{l}0(-0.63,0.81) \\
p=0.806\end{array}$ & $\begin{array}{l}1.2(-0.51,1.9) \\
p=0.001\end{array}$ \\
\hline
\end{tabular}

For abbreviations, see Table 1. Mixed model values listed as mean difference from reference time with $95 \% \mathrm{Cl}$. The reference time was set to 30 min after initiation of Impella CP support. A value of $P<0.05$ was considered significant

II trial demonstrated a lower risk of arrhythmia with norepinephrine among patients with shock. Moreover, norepinephrine was associated with improved survival compared to dopamine in a subgroup analysis of $280 \mathrm{pa}-$ tients with CS [32]. Avoidance of arrhythmia is pivotal in patients treated with the microaxial flow pump, given their functional dependence on adequate blood delivery from the right heart (preload). A recent randomized study that compared norepinephrine and epinephrine in 57 patients with AMICS demonstrated similar effects on perfusion pressure, but in the epinephrine group, a higher incidence of prolonged lactate-acidosis, tachycardia, and refractory CS was observed, leading to premature termination of the study [33]. In the present study, we did not observe any adverse metabolic effects of epinephrine, which may be a result of dosage or duration of therapy. However, we observed tachycardia with epinephrine as well as for dopamine and phenylephrine, which is concerning both in terms of adequate coronary perfusion and risk of arrhythmia.

The increase in HR with phenylephrine is intriguing, and current study offers no direct insight in the reason for this. The increase was not driven by one or two outliers or due to cardiac arrhythmias. Rather, we observed a uniform increase in HR. Whether this was caused by reflex tachycardia due to reduction in perfusion (reduction in $\mathrm{SvO} 2)$ or whether it was a direct effect of the drug in Danish landrace pigs is speculative. Compared to dopamine that also caused significant increase in HR, the effect of dopamine was associated with increase in $\mathrm{SvO} 2$ whereas phenylephrine was not, suggesting the unfavorable effect of phenylephrine not solely to be driven 


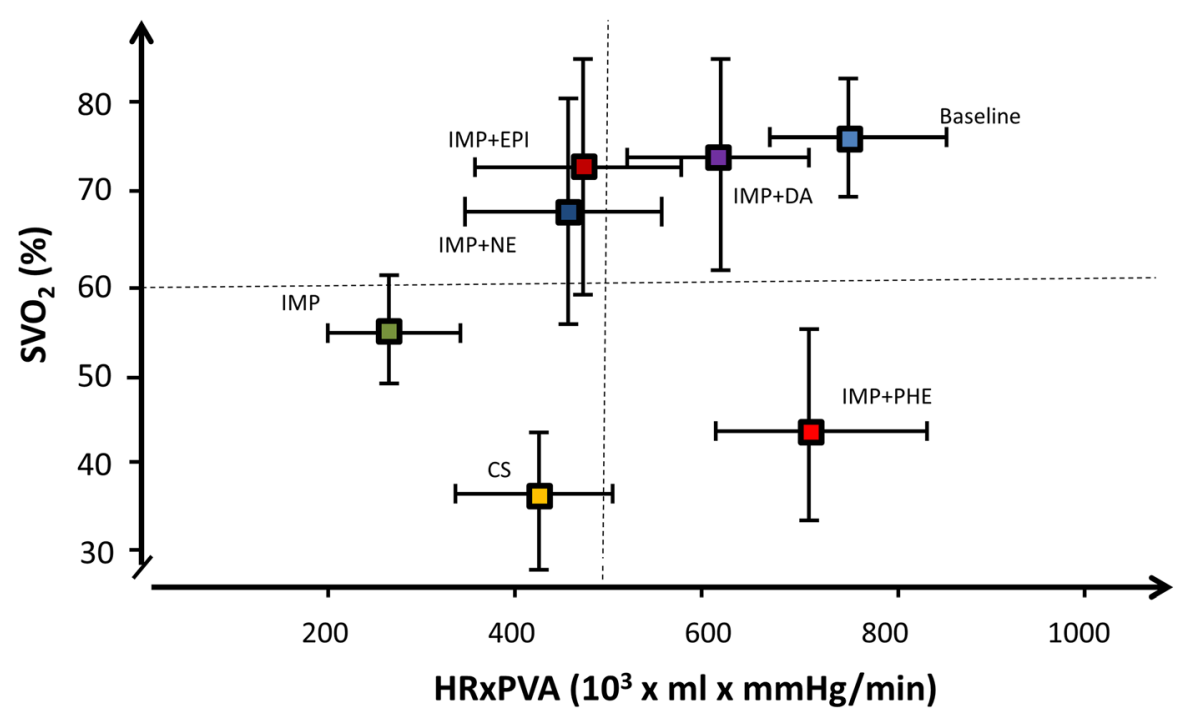

Fig. 3 Correlation of oxygen delivery with cardiac work. $\mathrm{SvO}_{2}$ ( $y$-axis) represents the mean mixed venous oxygen saturation and HR $\times$ PVA ( $x$-axis) represents the mean cardiac work

by HR. Thus, the current study warrants caution to use of vasoconstrictor alone while on LV support with Impella CP in AMICS.

\section{Limitations}

In this study, vasoactive drugs were administered at what is considered equipotent doses and not titrated against a predefined target MAP, as done in the clinical setting. The doses of dopamine and phenylephrine used in this study might have been too low compared to the new vasoactive inotropic score [34]. In our opinion, a higher dose of phenylephrine would not be beneficial given the adverse effect of the low dose used in this study. Also, increasing the dopamine dose would result in vasoconstriction (alpha-receptor stimulation) with the risk of negative impact on cardiac work and coronary perfusion. The experimental setting based on a standard operating procedure used in this study aids in reproducibility and reducing the variability involved in testing the physiological effects of drug therapies in an acute setting. A high number of animals would have been required to compare the effects inter-individual. Despite being clearly superior, this was not feasible in terms of time required and expenses. Thus, we chose to do the cross-over design and make intraindividual comparisons to allow for a lower number of animals. However, the small sample size of the study is a limitation and may result in a type II error. Given the risk of hemodynamic instability, we did not include washout periods between drug infusions. Nonetheless, we do not expect a carryover effect of a previous drug infusion as the vasoactive agents have a short half-life, and the measurements were taken at the end of each infusion. The diuresis was not recorded systematically as we in design of study considered the individual duration of intervention too short to have confidence that the diuresis during each intervention was not mostly carry over effect of previous. The crossover design and statistical analyses were undertaken considering the potential effect of the timing of the interventions. Phenylephrine was administered in all the pigs at the end of the experiment due to its long half-life. The pigs may have developed more severe CS in the end, which could have affected the results. We attempted to adjust for this effect by using the linear mixed model and believe that the adverse effect of phenylephrine observed in this study reflects the drug's effect and not a timedependent artifact. The experimental observation period in this study is probably too short and may not reflect the long-term effects of concomitant vasoactive treatment and LV unloading in AMICS. Given the similar body size and adrenoceptor distribution and function among pigs and humans, the results may apply to the human treatment of CS [24].

\section{Conclusion}

In this preclinical study, mechanical circulatory support with Impella CP in severe CS lowered cardiac workload, but perfusion pressure was inadequate in most pigs. The addition of catecholamines increased perfusion pressure and oxygen delivery but at the expense of increased cardiac work, most for dopamine. Vasoconstriction with phenylephrine caused an increase in cardiac work without any increase in oxygen delivery. Thus, a support strategy based on Impella CP and low-dose catecholamine preferably norepinephrine to avoid arrhythmias seems optimal to balance oxygen delivery and cardiac work. The study 
results suggest great caution when using vasoconstrictors such as phenylephrine in the setting of CS.

\begin{abstract}
Abbreviations
AMI: Acute myocardial infarction; AMICS: Acute myocardial infarction complicated by cardiogenic shock; Cl: Confidence interval; CO: Cardiac output; CS : Cardiogenic shock; Ea: Arterial elastance; Ees: End-systolic pressure-volume relationship; HR: Heart rate; LV : Left ventricle; LVEDP: Left ventricular end-diastolic pressure; LVEDV: Left ventricular end-diastolic volume; LVESP: Left ventricular end-systolic pressure; LVESV: Left ventricular endsystolic volume; LLM: Linear mixed model; MAP: Mean arterial blood pressure; PE: Potential energy; PV : Pressure volume; PVA : Pressure volume area; $\mathrm{SVO}_{2}$ : Mixed venous oxygen saturation; SW: Stroke work

\section{Acknowledgements}

We gratefully acknowledge the staff at the Biomedical Laboratory at the University of Southern Denmark. We thank statistician Inge Petersen for statistically assistance and medical writer Uma Chandrasekaran for grammatical proofreading of the manuscript. Lastly, we thank Abiomed, University of Southern Denmark, and Region of Southern Denmark for research grants.
\end{abstract}

\section{Authors' contributions}

All authors have made substantial contributions to the work; NLJU, OKLH, ABSB, PHF, JJ, LOJ, HS, HBR, and JEM have contributed to the study design, study conduct, data collection, and revision of the manuscript. NLJU have performed the data analysis. NLJU, OKLH, ABSB, PHF, JJ, LOJ, HS, HBR, JEM, ERE, and BYC have drafted the manuscript, and all authors approved the submitted version.

\section{Funding}

The study received a grant from Abiomed, and NLJU was supported by a research grant from Abiomed, Region of Southern Denmark, and University of Southern Denmark. The funder did not have any influence of the design of the study or the data collection, analysis, and interpretation of data or the content of the manuscript.

\section{Availability of data and materials}

The datasets from the current study are available from the corresponding author on reasonable request.

\section{Ethics approval and consent to participate}

The study was approved and conducted per guidelines of the Danish Animal Experiments Expectorate (authorization number: 2016-15-00951).

\section{Consent for publication}

Not applicable

\section{Competing interests}

The study received a grant from Abiomed. NLU and OKLH have received travel compensation by Abiomed. JEM has received research grants and speaker's fee from Abiomed.

\section{Author details}

'Department of Cardiology, Odense University Hospital, J. B. Winsløwsvej 4, Odense C, Denmark. 2Department of Cardiology, Rigshospitalet, Copenhagen University Hospital, Copenhagen, Denmark. ${ }^{3}$ Department of Anesthesiology and Intensive Care, Odense University Hospital, Odense, Denmark. ${ }^{4}$ Institute for Medical Engineering and Science, Massachusetts Institute of Technology, Cambridge, Massachusetts, USA. ${ }^{5}$ Cardiovascular Division, Brigham and Women's Hospital, Harvard Medical School, Boston, Massachusetts, USA. ${ }^{6}$ Department of Cardiothoracic Anaesthesia, Rigshospitalet, Copenhagen University Hospital, Copenhagen, Denmark.

Received: 11 December 2019 Accepted: 4 March 2020

\section{Published online: 18 March 2020}

\section{References}

1. Helgestad OKL, Josiassen J, Hassager C, Jensen LO, Holmvang L, Sørensen A, et al. Temporal trends in incidence and patient characteristics in cardiogenic shock following acute myocardial infarction from 2010 to 2017: a Danish cohort study. Eur J Heart Fail. 2019. https://doi.org/10.1002/ejhf. 1566 [Epub ahead of print].

2. Goldberg RJ, Spencer FA, Gore JM, Lessard D, Yarzebski J. Thirty-year trends (1975 to 2005) in the magnitude of, management of, and hospital death rates associated with cardiogenic shock in patients with acute myocardial infarction a population-based perspective. Circulation. 2009;119(9):1211-9. https://doi.org/10.1161/CIRCULATIONAHA.108.814947.

3. Kolte D, Khera S, Aronow WS, Mujib M, Palaniswamy C, Sule S, et al. Trends in incidence, management, and outcomes of cardiogenic shock complicating ST-elevation myocardial infarction in the United States. J Am Heart Assoc. 2014;3(1):e000590. https://doi.org/10.1161/JAHA.113.000590.

4. De Luca L, Olivari Z, Farina A, Gonzini L, Lucci D, Di Chiara A, et al. Temporal trends in the epidemiology, management, and outcome of patients with cardiogenic shock complicating acute coronary syndromes. Eur J Heart Fail. 2015;17(11):1124-32. https://doi.org/10.1002/ejhf.339.

5. Rathod KS, Koganti S, Iqbal MB, Jain AK, Kalra SS, Astroulakis Z, et al. Contemporary trends in cardiogenic shock: incidence, intra-aortic balloon pump utilisation and outcomes from the London Heart Attack Group. Eur Heart J Acute Cardiovasc Care. 2018;7(1):16-27. https://doi.org/10.1177/ 2048872617741735

6. Maack C, Eschenhagen T, Hamdani N, Heinzel FR, Lyon AR, Manstein DJ, et al. Treatments targeting inotropy. Eur Heart J. 2019;40(44):3626-44. https://doi.org/10.1093/eurheartj/ehy600.

7. Furer A, Wessler J, Burkhoff D. Hemodynamics of cardiogenic shock. Interv Cardiol Clin. 2017;6(3):359-71. https://doi.org/10.1016/j.iccl.2017.03.006.

8. Mebazaa A, Combes A, van Diepen S, Hollinger A, Katz JN, Landoni G, et al. Management of cardiogenic shock complicating myocardial infarction. Intensive Care Med. 2018;44(6):760-73. https://doi.org/10.1007/s00134-0185214-9.

9. Thiele H, Zeymer U, Neumann F-J, Ferenc M, Olbrich H-G, Hausleiter J, et al. Intraaortic balloon support for myocardial infarction with cardiogenic shock. N Engl J Med. 2012 Oct 4;367(14):1287-96. https://doi.org/10.1056/ NEJMoa1208410.

10. Rohm CL, Gadidov B, Leitson M, Ray HE, Prasad R. Predictors of mortality and outcomes of acute severe cardiogenic shock treated with the Impella device. Am J Cardiol. 2019;124(4):499-504. https://doi.org/10.1016/.amjcard. 2019.05.039.

11. Jentzer JC, Wiley B, Bennett C, Murphree DH, Mark T, Kashani KB, et al. Temporal trends and clinical outcomes associated with vasopressor and inotrope use in the cardiac intensive care unit. Shock. 2019. https://doi.org/ 10.1097/SHK.0000000000001390 [Epub ahead of print].

12. Overgaard CB, Džavík V. Inotropes and vasopressors: review of physiology and clinical use in cardiovascular disease. Circulation. 2008;118(10):1047-56. https://doi.org/10.1161/CIRCULATIONAHA.107.728840.

13. Jentzer JC, Coons JC, Link CB, Schmidhofer M. Pharmacotherapy update on the use of vasopressors and inotropes in the intensive care unit. J Cardiovasc Pharmacol Ther. 2015;20(3):249-60. https://doi.org/10.1177/ 1074248414559838

14. Burkhoff D, Sayer G, Doshi D, Uriel N. Hemodynamics of mechanica circulatory support. J Am Coll Cardiol. 2015;66(23):2663-74. https://doi.org/ 10.1016/j.jacc.2015.10.017.

15. Uriel N, Sayer G, Annamalai S, Kapur NK, Burkhoff D. Mechanical unloading in heart failure. J Am Coll Cardiol. 2018;72(5):569-80. https://doi.org/10.1016/ j.jacc.2018.05.038.

16. Møller-Helgestad OK, Hyldebrandt JA, Banke A, Rud CS, Udesen NL, Linde $L$, et al. Impella CP or VA-ECMO in profound cardiogenic shock: left ventricular unloading and organ perfusion in a large animal model. Eurolntervention. 2019;14(15):e1585-92. https://doi.org/10.4244/EIJ-D-1800684.

17. Møller-Helgestad OK, Ravn HB, Møller JE. Large porcine model of profound acute ischemic cardiogenic shock. Methods Mol Biol. 1816;2018:343-52. https://doi.org/10.1007/978-1-4939-8597-5_27.

18. Senzaki $\mathrm{H}$, Chen $\mathrm{CH}$, Kass DA. Single-beat estimation of end-systolic pressure-volume relation in humans: a new method with the potential for noninvasive application. Circulation. 1996;94(10):2497-506.

19. Sagawa K. The end-systolic pressure-volume relation of the ventricle: definition, modifications and clinical use. Circulation. 1981;63(6):1223-7.20.

20. Suga H, Sagawa K. Instantaneous pressure volume relationships and their ratio in the excised, supported canine left ventricle. Circ Res. 1974;35(1):117-26.

21. Burkhoff $D$, Sagawa K. Ventricular efficiency predicted by an analytical model. Am J Phys. 1986;250(6 Pt 2):R1021-7. 
22. Walley KR. Left ventricular function: time-varying elastance and left ventricular aortic coupling. Crit Care. 2016;20:270. https://doi.org/10.1186/ s13054-016-1439-6.

23. Dünser MW, Takala J, Brunauer A, Bakker J. Re-thinking resuscitation: leaving blood pressure cosmetics behind and moving forward to permissive hypotension and a tissue perfusion-based approach. Crit Care. 2013;17(5): 326. https://doi.org/10.1186/cc12727.

24. Guimarães S, Moura D. Vascular adrenoceptors: an update. Pharmacol Rev. 2001;53(2):319-56.

25. Foster RW. The pharmacology of pressor drugs. Br J Anaesth. 1966;38(9): 690-704.

26. Beurton A, Ducrocq N, Auchet T, Joineau-Groubatch F, Falanga A, Kimmoun $A$, et al. Beneficial effects of norepinephrine alone on cardiovascular function and tissue oxygenation in a pig model of cardiogenic shock. Shock. 2016;46(2):214-8. https://doi.org/10.1097/SHK.0000000000000579.

27. Karami M, den Uil CA, Ouweneel DM, Scholte NT, Engström AE, Akin S, et al. Mechanical circulatory support in cardiogenic shock from acute myocardial infarction: Impella CP/5.0 versus ECMO. Eur Hear J Acute Cardiovasc Care. 2019. https://doi.org/10.1177/2048872619865891 [Epub ahead of print].

28. Schrage B, Ibrahim K, Loehn T, Werner N, Sinning JM, Pappalardo F, et al. Impella support for acute myocardial infarction complicated by cardiogenic shock. Circulation. 2019;139(10):1249-58. https://doi.org/10.1161/ CIRCULATIONAHA.118.036614.

29. Jensen PB, Kann SH, Veien KT, Møller-Helgestad OK, Dahl JS, Rud CS, et al. Single-centre experience with the Impella CP, 5.0 and RP in 109 consecutive patients with profound cardiogenic shock. Eur Heart J Acute Cardiovasc Care. 2018;7(1):53-61. https://doi.org/10.1177/2048872617743194.

30. Levy B, Buzon J, Kimmoun A. Inotropes and vasopressors use in cardiogenic shock: when , which and how much? Curr Opin Crit Care. 2019;25(4):38490. https://doi.org/10.1097/MCC.0000000000000632.

31. Ibanez B, James S, Agewall S, Antunes MJ, Bucciarelli-Ducci C, Bueno H, et al. 2017 ESC guidelines for the management of acute myocardial infarction in patients presenting with ST-segment elevation. Eur Heart J. 2018;39(2):119-77. https://doi.org/10.1093/eurhearti/ehx393.

32. Backer D, Biston P, Devriendt J, Madl C, Chochrad D, Aldecoa C, Brasseur A, Defrance $P$, Gottignies PVJ. Comparison of dopamine and norepinephrine in the treatment of shock. N Engl J Med. 2010;362(9):779-89. https://doi.org/ 10.1056/NEJMoa0907118.

33. Levy B, Clere-Jehl R, Legras A, Morichau-Beauchant T, Leone M, Frederique $G$, et al. Epinephrine versus norepinephrine for cardiogenic shock after acute myocardial infarction. J Am Coll Cardiol. 2018;72(2):173-82. https://doi. org/10.1016/j.jacc.2018.04.051.

34. Vallabhajosyula S, Jentzer JC, Kotecha AA, Murphree DH, Barreto EF, Khanna AK, et al. Development and performance of a novel vasopressor-driven mortality prediction model in septic shock. Ann Intensive Care. 2018;8(1): 112. https://doi.org/10.1186/s13613-018-0459-6.

\section{Publisher's Note}

Springer Nature remains neutral with regard to jurisdictional claims in published maps and institutional affiliations.

Ready to submit your research? Choose BMC and benefit from:

- fast, convenient online submission

- thorough peer review by experienced researchers in your field

- rapid publication on acceptance

- support for research data, including large and complex data types

- gold Open Access which fosters wider collaboration and increased citations

- maximum visibility for your research: over $100 \mathrm{M}$ website views per year

At BMC, research is always in progress.

Learn more biomedcentral.com/submissions 